\title{
On the Internal Dynamics of the Conflict/Violence Process: A Discussion with Randall Collins
}

\author{
Jérôme Ferret ${ }^{1} \cdot$ Randall Collins $^{2}$
}

Published online: 30 May 2017

(C) The Author(s) 2017. This article is an open access publication

Why study social conflict in the end of 1960s?

There were external and internal reasons. In the USA, the growth of the civil rights movement over racial discrimination, and then the anti-war movement against the Vietnam War, were mobilizations that many university students, including myself, took part in.

What were the main criticisms you made of «big » theories of stratification? (Marx, Weber, Parsons, Dahrendorf, ...) Can we say that you did an interpretation of Weber, "left wing"?

Here the internal field of sociology was making one of its periodic realignments. In the 1930s, 40s, and 50s, Parsons raised the level of sophistication by arguing that Durkheim formulated the central question, what holds society together, and showed that it could not be done by isolated individuals with purely selfish and material interests. Parsons combined Durkheim's pre-contractual solidarity with Weber's valueorientations of the world religions to make sociology into a theory of society at all levels, from the socialization of the individual (which in the 1950s Parsons was explaining by the socializing effects of the Freudian superego) up to the trajectories of world history. This was an impressive synthesis but other sociologists were showing its flaws. Hans Gerth and C. Wright Mills (among others) showed that Weber also said much about conflict and domination; Herbert Blumer protested against omitting the

This discussion is the result of e-mail exchanges with Randall Collins between 2014 and 2015. A first version of this article was published in L'émergence d'un mouvement en faveur de la désescalade est encore et toujours le résultat d'une dynamique temporelle. Entretien avec Randall Collins, Négociations, vol. 24, no. 2, 2015 , pp. $165-180$.

Jérôme Ferret

jerome.ferret@ut-capitole.fr

Randall Collins

Collinsr@sas.upenn.edu

1 Université Toulouse 1 Capitole, Toulouse, France

2 University of Pennsylvania, Philadelphia, PA 19104, USA 
interpretations made by the actor in the situation; Berger and Luckmann publicized the social construction of reality, and Garfinkel showed with novel research methods how it is done. Marxism came into US sociology largely with the radical student movement, but it was mediated by sociologists like Dahrendorf, who shifted Marxism from its focus on the working class to a focus on how middle-class and bureaucratic workers could also be mobilized. This was an intellectually exciting period. Like some others, I concluded that a "left-Weberian" position could combine the strengths of Weber and Marx, give greater understanding of organizations, cultural-identity groups, and movements, and that Durkheim's insights could be brought in via the micro-sociology of Goffman.

In this direction, can I say that you did a Phenomenology of Conflict? (Social Conflict understood as Self constructed subjective worlds; others controlling subjective experiences; others control who oppose them).

There was some influence from phenomenology, probably from reading Sartre in my student years. But where Sartre could say, hell is other people, my interpretation is much closer to Goffman and Durkheim: the self is always collectively constructed. Conflict is largely between groups and from individuals constructed as identities when groups focus attention upon them as distinct individuals.

What do you think about this proposition? In the end, we speak not so much of structuring conflicts, we speak more about domination, power, symbolic violence... of some on the others, material, symbolic and all this is a little bit static, very close of structural-functionalism, or sociology of social stratification even if we have some extensions of Social Conflict theory in other social fields like sex, age, family dominance? What about the positive role of negative but structuring (permanent?) conflicts as in the industrial world the structuring conflict between working class and elites for the control of social, cultural, values, objectives?

What are the sources of social conflict? Anything can become an object of conflict if groups or persons focus upon it from conflicting perspectives. That means, to focus upon something in a way that it becomes the target of trajectories of action that are at crosspurposes with each other. It is easiest to see this if we examine historically some social institutions that at one time were not objects of conflict, but become conflictual in another time. An example is conflict inside the family household. In medieval feudal-patrimonial households, there was very little conflict between masters and servants, or between parents and children, husbands and wives, because the main trajectories of conflict were between households as the main unit of political and economic organization; outside a household an individual had no chance of pursuing a life-course. When the bureaucratic state displaced the household as the unit of power, and registered individuals as subjects of career-trajectories in institutions of education, health, public service, work etc., the household became an arena in which individual-level conflicts could take place. The main principle is that the conditions that mobilize purposeful action also make possible conflicts. Some old sources of conflict have disappeared (most people in the modern bureaucratic world could not engage in tribal conflict even if they wanted to), while new sources of conflict are being developed because of new ways of mobilizing (e.g. conflicts between different groups of sports fans or music fans). The future will no doubt invent forms of conflict that we have not yet imagined.

Is there not a danger to consider only a "winners losers, "win lost", "win win" perspectives? To lock, to reduce social conflict theory as a crisis management theory or peace building theory? Is there not a danger to speak only about the strategic, war conflicts, armed groups, military groups? Napoleonic' Model? 
I agree; many conflicts - i.e. trajectories of action at cross-purposes - do not have winners and losers, because the conflict is a stalemate, or because the conflict loses intensity or aborts. Even conflicts which have an ostensibly clear goal-e.g. winning a war-often have outcomes that were not imagined when the conflict began. One has only to think of the unexpected outcomes of most of the wars from the First World War onwards to the recent Iraq wars, or the Syrian civil war, to see that concepts of winners and losers are too simple for social reality.

My reason for analyzing the dynamics of wars is not to make wars the archetype of all conflicts, but more the opposite reason: to show that even in military violence, social organization and emotional domination are more important than physical violence. Even war, which seemingly aim at winning via physical destruction of the opponent, actually depends in its outcomes on breaking down enemy organization and its emotional solidarity. The dynamics of violent conflict are more closely related to the dynamics of emotional focus in interaction rituals, than to material resources.

And in this perspective, what about a conflict as a social relationship without winners, without losers, without end, issues, analyzed only as a space, field of relations with in the same time autonomy of the actors but in the same time interdependence (Elias, concept of configuration or concept of antagonism in Simmel's theory)?

This seems to me to go too far, and to make conflict dissolve into a purely abstract conceptual scheme. It is not clear that all fields of social action are equally structured by conflict. Some fields take their major lines of structuring and of action-trajectories from conflict: these conflict-structured fields include politics, and the intellectual world. Politics, because the most dramatically mobilizing issues are where there is a strong antagonism, if not with an external enemy, then with an internal opponent; thus to make a career as a politician is to seek out conflicts that make one prominent; a politician without issues to dispute over would never become well-known. The intellectual world, too, generates creative ideas, and thus famous thinkers, when a new generation breaks away from the ideas of the older generation, and also when they split among themselves into rival schools of thought. As I analyzed in The Sociology of Philosophies, famous creativity happens when networks reorganize themselves to fill out the small number of rival positions available in the intellectual attention space.

On the other hand, there are some fields that do not seem to be intrinsically organized by conflict. The realm of economic production and distribution is one of these. It is true that capitalism is a particular economic form that is organized around conflict; but non-capitalist economies have existed in the past, and probably will exist in the future. The specific forms of conflict among rival monopolists and financiers, or between employers and workers, are not intrinsic to economic relations, unlike politics, which could not really exist if there were no conflict.

\section{Radical Micro Interactions, Time Dynamics and Role of Neutrals, Allies or Peace Makers}

Why did you make an "interactionist turn" in your Social Theory Conflict? Later, how evolved your interactionist perspective? 
I always had an interest in micro-interaction, having been trained in psychology, and then studying with Blumer and Goffman, and working among the California ethnomethodologists. I shifted my emphasis largely because of the pragmatics of the sociological field; there was less interest in my work on geopolitics and developments on Weber, than in my micro-sociology. The research field also developed a new concern for emotions, which must be studied in micro-interactions; emotions are much better way to conceptualize abstract concepts like norms and values, because we can directly observe emotions in people's faces, movements, voices, and bodies. Thus the part of the social world that formerly was considered to be non-rational, or transrational, non-instrumental, etc. can now be studied in a very concrete way. Theorists like Parsons, or Pareto, or for that matter Elias and Foucault, talked about culturaldispositional factors that change historically but seem to operate from overhead; but now the methods of micro-sociology make it possible to look at emotions as they actually take place in specific kinds of social interactions. Locating norms, values, predispositions, habitus and other such conceptions in the actual processes of interaction among persons enables us to see the dynamics that produce, sustain, and change such emotional-evaluative-motivational experiences. The theory of Interaction Rituals puts the key causal conditions and outcomes into a model that predicts what people will feel, think, say, and do in specific situations of their chain of social interactions.

Why (I can make a mistake) this form of radicalization of your theory, towards a paradigm of extremely micro analysis, thus it does not bridge well with other approaches?

Several reasons. Micro-sociology has become a very creative research front. Like other sociologists, I take advantage of the new techniques of research introduced by Goffman, by the followers of Garfinkel, by ethnographers of everyday life, by new technologies of highly portable photography and videos. What one observes from these techniques is what happens in specific situations; they are techniques of microsociological research. Add to this an argument which I have modified from Blumer and Garfinkel: everything that happens in the social world happens in micro-situations. Everything else that sociologists talk about—structures, "societies," social classes, ethnic groups - all exist as particular kinds and patterns of micro-interaction. All data is gathered in micro-situations, and then is transformed into something more abstract. This means that the key to what happens must be in the micro-situations, because nothing else exists except more micro-situations. But such an argument is not very convincing in the abstract, unless one can show that we learn something new from examining the features of micro-interactions. The ethnomethologists were not very successful in making explanations that actually told us something new about states, organizations, social movements, etc. But we learn something new from microsociological research on conflict.

\section{E-Escalation/Polarization Process}

More recently, in your ASA dissertation on C-Escalation/D-Escalation, you talked about dynamics. How describe the process, the time-dynamics?

Time-dynamics is an attempt to theorize social processes as they occur in time. Most theorizing about causality is comparative statics. Even when some mathematical models enter variables in a sequence, we are still theorizing in a realm of abstraction, not the real 
world of events in which things happen and we participate in them. Events take a certain amount of time; they have qualities like sudden, slow, accelerating, static, fading or abruptly ending. Time-dynamics are what gives events their emotional qualities: surprising, shocking, exciting, normal, boring, tedious. And probably vice versa: the emotional dynamics of human interaction are what make the patterns of events in time.

This is a field that we are only now beginning to study. A simple question: how long do events last? When the 9/11/2001 attack took place, I realized here was an opportunity to examine the time-dynamics of Simmel's theory that external conflict brings internal solidarity. Americans began to manifest their solidarity by putting up flags on houses and cars; I began to count the flags in various places, repeatedly for over a year. This symbolic solidarity display went up very rapidly, reaching its peak within 2 weeks; then it stayed at its height for 3 months. During this time there were many ceremonial events, full of emotion; also a very strong pressure to national conformity, and also events of political hysteria such as fear of poison attacks. After 3 months the opposition began to reappear, and by 6 months the level of flag display had fallen to about half its peak, with a long slow decline for the rest of the year. Examining historical cases of sudden onsets of national conflict, I have suggested that there is a 3 month solidarityand-hysteria zone, during which most atrocities take place (this was the case during the Spanish Civil War, for instance); then normal political splits begin to re-emerge. This is an example of time-dynamics in large-scale conflict. The emotional pressure is so strong during the first 3 months that people cannot act except in the prevailing mode of solidarity, however irrational and destructive it is. This was the pattern in all the European states at the beginning of the First World War. Intelligent strategizing began to reappear later, but the organizational momentum set in motion was hard to overcome. That is to say, the beginning of a mass conflict relies on widespread emotional enthusiasm, that silences any possible opposition. After the 3-to-6 month cooling down period, the conflict can still continue but the militant faction now uses more coercive tactics and people follow along more with stoic determination than enthusiasm. Further time-dynamics could be developed which show when there are actual revolts against this coercion to continue fighting; the mutinies that took place in most of the armies during the 3rd and 4th years of the First World War may show the pattern. It is likely that time-dynamics are produced by more complex causality as well; additional variables can extend or shorten the basic time-patterns.

You explain the importance of Emotions, small scales conflict, talk, circulation of rumors. So, what could make rumors became realities? What is your definition of atrocities? What about the forward panic in this process? When does it happen?

Atrocities are events that people generally find to be outrageous, shocking to moral sensibilities of the time. Obviously this changes historically, and the kinds of violent displays of power that the Romans used during their campaigns would be considered terrible atrocities today, although at the time there was little outcry against them. Since the early twentieth century, Western sensibilities about what are considered atrocities have grown considerably. The causes of these changes in what is regarded as atrocities have not been well-analyzed sociologically, as we tend to take our moral sensibilities as natural; but it seems likely that the scope of atrocity as a social category will grow still further in the future.

In the general theory of counter-escalation (C-escalation), atrocities are whatever the people on each side regard as morally outrageous. Part of the polarization process is to take whatever the opponent does as outrageous; in small-scale quarrels, it may only be 
the things people say. In politics today, it frequently happens to accuse a political opponent of saying something that is racist, homophobic, etc.- and thus to make a political scandal out of their words. In un-violent political conflict, a scandal typically indicates the social construction of a mass mobilization to combat a perceived atrocity. Similarly in violent conflicts; here the process tends to include rumors, stories about what the enemy has done. Often these are stereotyped stories- enemies who rape pregnant women or kill babies; and later it generally turns out that the events are fabricated or exaggerated. Moreover, the process works on both sides. The opposing side, for their part, usually believes their own rumors, that their enemy has committed atrocities (rapes, assassinations, etc.) which we shall now revenge. This is the common pattern in communal violence between Hindus and Muslims in India, for instance. Rumors can become realities in this counter-escalation process; initially they may be untrue, or gross exaggerations of smaller incidents, but as c-escalation goes on, both sides tide produce real atrocities. Thus each side morally justifies each other.

Forward panic is a particular kind of conflict pattern. Not all atrocities are the results of forward panics, but forward panics generally produce an atrocity, since the end result is overkill (far more violence than necessary to win the conflict) and piling on (an attack by a large group against weak or unresisting victims). Forward panic begins with a phase of tension between two sides; then a phase in which the tension is suddenly released, as one side becomes weak and the other rushes forward into an attack. I have adopted the term from the military thinker Charles Ardent du Picq, who called it "flight to the front"- the pattern in which soldiers under fire will sometimes run wildly, not away from the enemy but towards him, firing wildly. It is a collective emotional process (that I called "hot rush", which is what it feels like physiologically), and it is set off when the equilibrium of two sides evenly held in the tension of conflict is transformed into a situation of one-sided emotional domination.

\section{Role of Neutrals/Third Parties/Allies during the Conflict in the Polarization Process, E-Escalation}

How can we describe the process when third parties, neutrals (unlookers in a riot, a fight) become allies? How can we evaluate, understand, measure the degree of enthusiasm or reluctance or whether when they remain neutral?

Empirically, in photos of a riot, the violence is carried out by a number of small groups of about 6 persons, who find an isolated enemy to attack. Most of the crowd stands back at a safe distance and observes. Many of them are making noise, supporting those who fight. They are allies in that sense, emotional allies, although they are doing nothing actively to help the fighters. When the enemy advances, this part of the crowd is the first to run away. Also some part of the crowd is more genuinely neutral; they come only out of curiosity, to see what is happening. Thus we can measure their degree of enthusiasm, reluctance, or neutrality by their behavior, their positions in the space of conflict (literally), their body postures, sounds and emotions.

What is the role of neutrals, third parties, allies in this process of keeping a confrontation from escalating? Is the size of the group mobilized important in the time dynamics of conflict?

A crowd can keep a conflict from escalating as long as the crowd is quite large compared to the size of the groups that are fighting. When there is a large crowd in a 
public place, and a fight breaks out between two individuals, how long and severe the fight will be depends on what the crowd does. If the crowd pays no attention, or is uneasy and avoids the fight, the fight stops. If the crowd cheers the fighters, they will have a longer fight (this typically happens when the crowd is waiting for an entertainment event to begin). But if a fight breaks out when there are 6 or more persons in the fight (especially if there are 6 or more on one side), the larger crowd has no effect on stopping them; the fighting crowd itself is big enough to act as its own crowd support. The process in all these variations is a Durkheimian one: the collective action of the group when it focuses its attention generates an emotional field, either for or against violence; and the effect of the crowd upon small numbers of individuals is overpowering.

Can you explain me this very interesting proposition? "You can keep a confrontation from escalating by keeping it at the level of stalled repetition until it deescalates, quite literally, from boredom".

Here we are discussing individuals in conflict. Such confrontations begin with staring at each other's face (as Americans say, "getting in your face"), arguing, making insults and gestures. There is the danger that the conflict will escalate into touches, pushes, and then violence. However, such confrontations often end without violence. This happens when the participants stay on the same level, mirroring each other's moves. In such arguments, people repeat the same phrase over and over again- it is useless to try to state a complex argument, and since both are talking at the same time, it is really a contest over getting the next conversational turn; a conflict on the paralinguistic level of speech acts, not in the contents of the speech itself. But this becomes tedious. After a period of time- usually less than $60 \mathrm{~s}-$ the participants lose their energy, their voices become lower; and finally one or the other will end the confrontation with a gesture of disgust. Thus, some practical advice: if you are an individual in a conflict, you can bring it to an end successfully by maintaining close equilibrium with your opponent, but not escalating the level of threat, until it de-escalates from boredom. This works well on the level of individual and small group conflicts. It is not clear that it works at the level of political and organizational conflicts, or conflicts between states.

\section{Role of Neutrals during the Conflict in the D-Escalation Process}

Why neutrals reappeared at the end, in d-escalation? What are the best positions for the third parties, neutrals, to negotiate steps that will eventually bring disengagement? Neutrals, despised at the beginning for their lack of solidarity, lack of courage, now with all the atrocities, culpability of leaders, violent actors, they are playing a central role?

The reappearance of neutrals comes from the time-dynamics of conflict, which is an emotional process. At the beginning, conflict groups generate Durkheimian solidarity and enthusiasm for the conflict; but over time, this enthusiasm begins to wane. Especially if the conflict remains in equilibrium, no one is winning, then the emotional level declines. This makes it possible for neutrals to reappear. At the beginning, the Durkheimian collectivity despises neutrals, since they are palpably immoral persons who do not join their righteous cause. But over time, with emotional equilibrium and 
material attrition, some of the adherents of the conflict lose their enthusiasm for continuing. In small conflicts and in social movements that depend on voluntary participation, the conflict can decline at this time merely because people stop coming out to the rallies and places of confrontation. In bigger, more organized conflicts, there is an bureaucratic machinery that is in motion (as in a war) that will carry on even without enthusiasm, so there needs to be more active processes to stop the conflict: neutrals who can now make connections to negotiate with the enemy; and also, internally, a movement for peace.

At the end, is D-escalation a new sort of conflict? With new actors? In the Descalation process, why does peace faction vs. victory faction depend on tactics more than ideology? Why do hardliners and compromisers not easily fit into ideological categories, but in the latter phase of a prolonged conflict? How do compromisers prevail?

The emergence of a movement that wants to de-escalate is the result of timedynamics. The collectivity that was once enthusiastic to fight their external enemy now loses enthusiasm, but some persons lose it more rapidly than others. This creates a new arena of conflict, now internal, over the question of whether to fight on to victory, or to bring the conflict to an end. As an American, I have witnessed and been part of these kinds of processes several times, with the Vietnam war peace movement, and in the Gulf wars and Afghanistan wars. The peace movement was never as popular in the public attention space as the patriotic faction (the victory faction), but in each case its policy prevailed in the end. A theoretical lesson for sociology is that we need to concentrate on a longer time-scale.

The patriotic faction has the stronger symbols - "What counts as losses for the deescalators are turned into symbols of our unstoppable drive towards victory"- i.e. they can use the dead and wounded, or the destroyed towns and monuments if the war is happening on your own land, as martyrs and memorials of our hatred for the enemy and the righteousness of our cause. The patriotic cause dominates the public ceremonies and thus the public definition of the situation. But the peace movement has the stronger weapon, the emotional dynamics of the people at large. Not that everyone has the same emotion; some are strong supporters of peace, who go to rallies and have their own solidarity and try to generate their own symbols (although no peace symbols have ever been as strong as national symbols and religious symbols). Other are simply tired of the war; and some, who were at one time happy to be in patriotic crowds, no longer find that exciting and turn their attention to something else. The peace movement benefits from people who are bored, apathetic, or just busy with other parts of their lives.

The peace movement is thus not an ideological coalition. True, it has some ideological factions in it, but they are not the majority, and not what makes the peace movement strong. It wins because it represents the emotional dynamics of a large and growing number of people. It is so to speak an anti-ideological faction, since it is the clear, vehement ideologies that generate the strongest conflict, hence the martyrs, and the willingness to go on fighting no matter the cost.

What are the social origins, identities of de-escalators, negotiators? What does it means? "They are, so to speak, latent possibilities in the structure of conflict space over time".

I haven't researched the social origins of de-escalators as compared to the victoryactivists, since my research has concentrated on the process of conflict itself. There is 
some data from peace researchers, but more is needed. My suggestion, however, is that social origins, a static condition, is not enough to explain how the number of deescalators grows over time. That is the meaning of the phrase "latent possibilities in the structure of conflict space"- it is always possible, in a conflict, to take one side or the other, but also to be opposed to entering the conflict at all; and that gives rise to another emergent possibility, opposing the peace movement. During the First World War attacks on those who did not want to continue to fight were quite vicious; they were called traitors, and sometime executed or imprisoned. From the time of the Vietnam War onwards, the factions became publically recognized and institutionalized as "hawks vs. doves". This is historically a good sign in the increasing legitimacy of a peace movement. On the other hand, there are some parts of the world where being neutral or in favor of peace is considered an act worthy of death. This is how the revolutionary movement in Syria turned into a vicious civil war that destroyed the lifechances of much of the population, especially those who did not want to fight. How to deal with such situations is the big challenge, for the theory and practice of peace.

\section{Policing}

In your book Violence, you speak about the role of police' organizations in the riots, mass demonstrations, crowds and more generally in confrontational dynamics and sometimes forward panics. What could be the role of police' organizations as neutrals, third parties in these conflicts' dynamics? What kind of relations, interactions can we observe between police forces and hardliners or compromisers?

In most demonstrations, the police (and crowd control forces) make up one side, the demonstrators the other side. Usually the target of the demonstrators has only a symbolic presence, or at most a material presence in the form of buildings that might be attacked. It is rare to have two active demonstrations- demonstrators and counterdemonstrators- who threaten each other; in such cases the police would be a third party, who should act to keep the peace, by keeping the two factions separate. One reason this configuration is so rare is because virtually all violent conflicts, at the moment when they are violent, are two-sided. Even if there are multiple factions, at the time they try to fight each other, they fall into two factions; above the number of two, the additional factions either attacking the same target as someone else, or stay out of the fight entirely.

This two-sided character of violence comes from the basic pattern of confrontational tension/fear. The confrontation itself generates tension; in order to get past this emotional barrier, the situation must turn into a disequilibrium in which one side feels much less tension than the other, so it can attack a weaker victim; or it must get the emotional support of the crowd as a Durkheimian collectivity. And even into the period of violence itself, participants find the situation a psychological blur, with perceptual and time-distortions, tunnel vision, a sense of confusion, a dream-state of emotional rush. I suggest this is the reason why a three-sided conflict is impossible; it is just too confusing. A two-sided structure simplifies the field enough so that fighters can act coherently- that is to say, as coherently as they do, because under these emotional conditions they do not control their violence very precisely.

The police also act this way when there are two opposing factions that they must control. Much of the time, they will join with one of the factions and attack the other; 
i.e. they will attack only one of the factions. The demonstrators who get attacked see this as favoritism on the part of the police, but it is also a result of the psychological near-impossibility of carrying out a three-sided conflict. There is another way this could be handled, which we see mainly where there are very small fights (a few fighters who both get arrested by the police), or where the third-party authority is much more powerful (the teacher who intervenes in the classroom by punishing all the children, no matter who is responsible for the fight). This takes a three-sided situation and turns it into a two-sided situation by fiat.

Can police be trained to handle such situations more carefully? Leaving aside the situation of policing a confrontation of demonstrators vs. counter-demonstrators, I would suggest that the main problem is for the police to avoid escalating the situation into a conflict between themselves and the demonstrators. Anne Nassauer (Freie Universitat Berlin) has carried out comparative research on when demonstrations stay peaceful, and when they result in violence, via pathways starting either from the police or from the demonstrators. There are a number of organizational patterns and microtactics that make an important difference. Police training could incorporate more of such sociology.

\section{Future of Social Conflict Theory: A Digital Turn?}

Can we consider that Internet and Social Medias are new confrontational spaces at distance? Virtual, numerical spaces that accelerate the diffusion of atrocities, narratives, rumors, for example?

This is an empirical question and we will find out more about it. As such electronic media have been used so far, they continue to fit the theoretical pattern that face-to-face conflict is difficult because it generates confrontational tension; and violence happens when emotional dominance is displaces emotional equilibrium in the confrontation. Digital media can be used in the non-confrontational phase, when the opponents are at a distance. In fact, such opponents rarely communicate with each other; each communicates with their own side, and with the unmobilized people in their network who they would like to bring in as allies. This could be analyzed with the C-Escalation/D-Escalation model of timedynamics. Digital media are good for spreading narratives and images; especially since these media tend to simplify as much as possible, they aid the polarization process. And since the digital media have no centralized control, there is no quality control over accuracy; these media are prime bases for spreading rumors. Even photo images can act as rumors, since they can be sent without attending to the surrounding context, and without giving accurate information about the identities of the persons represented. Thus we can expect that digital media mobilize social networks to engage in more conflict.

On the other hand, these media have such diverse connections that they cannot generate a single, common focus of attention. They are prone to multiple definitions of reality, and tend to disperse attention to many different directions. We can make this into a researchable question: when do digital media generate a stronger collective focus 
of attention (more people circulating the same messages), and when are they more scattered? The answer, from situations like mobilization in Cairo and Tehran, appears to be that physical action on the ground is what generates more common attention. The media can mobilize little groups of friends and acquaintances to go out to a place to demonstrate or fight, and the events there create focus of attention. There is some evidence, during the Green movement in Iran, that many people stayed home to watch, so that the media inhibited participation, when there was publicity about the opponents' repressive violence. So far it appears that digital media operate above all in the mobilizing phase and not in the conflict itself.

Are Computational Studies, Digital Studies able to analyze and understand the complexity of these new Virtual interactions? Social Conflict theory was a good theory for hierarchical systems but what about digital, complex, connexionist societies?

There has been a certain amount of enthusiastic propaganda about the digital age and how it is transforming society. In reality, it has been adding onto existing structures of society but not supplanting them, or even changing them very much. A powerful social conflict is when social groups organize to generate one big Durkheimian collective consciousness, full of resounding emotions; and this is best done where there is a big central place where people gather and the conflict with the enemy takes place- the historic central places of Paris, Petersburg, Tahrir Square, etc. The media can help publicize this but it does not eliminate the need to physically gather for the confrontation. Do the digital media change, if not the basic pattern of conflict, at least change its time-dynamics? Do the percentage of persons who are networked electronically in various ways (broadcast, point-to-point, etc) make the mobilization phase more rapid? Do they make the 3-month solidarity-and-hysteria zone shorter, or spread it out longer? Is the de-escalation phase more likely or less likely to happen sooner when there are many or few people digitally connected? Do digital connections facilitate the growth of a peace movement, or mainly just of a polarized hardline movement? These are researchable questions and sociologists will soon find out.

We have hardly touched on the real new danger of the cyber-connected world. That is conflict that occurs in the digital networks themselves. Cyber-war would be attacking or destroying the network. Some of this already happens, with government attacks on servers, and hackers' attacks on organizations, usually denial-of-service through overload attacks. More serious attacks could disrupt financial transfers, or electricity, or transportation control, and thus could have material consequences as devastating as bombs. The message of sociological theory of conflict here is more pessimistic. It is face-to-face conflict that is emotionally difficult to carry out; and these difficulties result in local stalemates, and in larger peace settlements. But attacks over cyber networks are emotionally easy; there is no confrontational tension, since the attacker never sees the victim, indeed does not even have to think the victims are real persons. The most important possibility, on the theoretical level, is not that digital media will transform existing kinds of human conflicts, but that cyberwar becomes an easy form of destruction.

Open Access This article is distributed under the terms of the Creative Commons Attribution 4.0 International License (http://creativecommons.org/licenses/by/4.0/), which permits unrestricted use, distribution, and reproduction in any medium, provided you give appropriate credit to the original author(s) and the source, provide a link to the Creative Commons license, and indicate if changes were made. 